\title{
Unusual Cases of Ocular Trauma
}

\author{
Rohan Kapoor ${ }^{1}$, Nitin Batra ${ }^{2}$ \\ 1, 2 Department of Ophthalmology, Christian Medical College, Ludhiana, Punjab, India.
}

\section{INTRODUCTION}

Ocular trauma has been described as one of the major aetiologies of monocular and non-congenital visual impairment and blindness in all parts of the world. Eye trauma constitutes $7 \%$ of all bodily injuries and $10 \%-15 \%$ of all eye diseases. ${ }^{1}$ Over 2.4 million eye injuries occur each year in The United States of America. ${ }^{2}$ Globally, there are approximately 1.6 million people who are blind from eye injuries, 2.3 million are bilaterally visually impaired, and 1.9 million have unilateral visual loss. ${ }^{3,4}$ Ocular trauma can be classified as closed and open globe injuries. Open globe injuries can be a rupture, penetrating injury, perforating injury or intra ocular foreign body. ${ }^{5} \mathrm{~A}$ perforating injury is defined as an injury that consists of two full thickness wounds one entry and one exit wound. ${ }^{6}$ It usually occurs due to a projectile object travelling at a high velocity and kinetic energy that is capable of penetrating two opposite coats of the globe. Perforation injuries are common and cause severe visual impairment. Panda et al. presented a profile of ocular trauma in Delhi in which they observed that among the type of injuries, perforating injuries accounted for $75.3 \%$, blunt injuries for $20.5 \%$ and extra- ocular for $4.2 \%$ of the total number of ocular trauma cases. Further the visual outcome in perforating injuries was > 6/12 in $14 \% ; 6 / 18-6 / 60$ in $14 \%$ and less than $6 / 60$ in $55.2 \%$ of the cases. ${ }^{7}$

Profile of ocular trauma varies with country, geography, industrialisation and development of the place. These injuries do not occur as random events and there is evidence that some individuals are at increased risk because of exposure to hazards and/or inability to avoid or detect hazards. ${ }^{8}$ Some individuals are at increased risk of eye injury as a result of their occupation. Small scale and large-scale industrial workers constitute a group of individuals at high risk. These workers are exposed to such hazards as flying metal chips, burns in the eye and injury from radiation. ${ }^{9}$ Ludhiana and neighbouring areas are heavily industrialised mainly, with metalrelated products and therefore, there are more chances of industrial ocular trauma. We are reporting two unusual cases related to ocular trauma. The first one is that of an alleged accidental injury to the right eye with a piece of hack saw blade whereas the second case report is that of a dental student who injured his eye by orthodontic wire which is used for making braces.
Corresponding Author: Dr. Rohan Kapoor, Room No. 2005, JDH, Brown Road, Christian Medical College, Ludhiana - 141008, Punjab, India. E-mail: rohan.kapoor827@gmail.com

DOI: $10.14260 / j e m d s / 2022 / 61$

How to Cite This Article:

Kapoor R, Batra N. Unusual cases of ocular trauma. J Evolution Med Dent Sci 2022;11(01):318-321, DOI: $10.14260 / \mathrm{jemds} / 2022 / 61$

Submission 13-12-2021,

Peer Review 20-12-2021,

Acceptance 03-01-2022,

Published 31-01-2022.

Copyright (C) 2022 Rohan Kapoor et al. This is an open access article distributed under Creative Commons Attribution License [Attribution 4.0 International (CC BY 4.0)] 


\section{PRESENTATION OF CASE}

Case - 1

A 21-year-old male with no previous ocular problem was brought to the emergency service, two hours after an alleged injury to the right eye with a hack saw blade. He was crossing a road while a man was sharpening the blade on a machine by the road side. A long piece of the saw blade broke and hit him over the right eyebrow.

The patient was fully conscious and stable when he was brought to the emergency service. A complete general physical examination along with a thorough ocular examination was done. The visual acuity in the right eye was only perception of light and the projection of rays was faulty, while the fellow eye had a visual acuity of $6 / 6$.

Local examination revealed a full thickness laceration over the right eyebrow through which the hack saw blade had penetrated. About a six-inch length of the blade could be seen protruding out from the entry site over the right eyebrow (Figure 1). The extra ocular movements were absent in all directions of gaze. Periorbital ecchymosis and oedema were also noted. The anterior segment examination revealed a full thickness scleral laceration (entry wound), with the hack saw blade embedded in the globe. The exit wound could not be assessed due to the severe periorbital oedema. Total hyphaemia was noted in the anterior chamber thus obscuring other anterior segment details. Prolapsed uveal tissue could be seen near the entry wound. Examination of the fellow eye revealed no abnormalities. The X-ray of orbit showed that the hack saw blade was lodged deep inside the facial bones. It had perforated the globe and after traversing the maxillary sinus had reached up to the palatine bone (Figure 2).
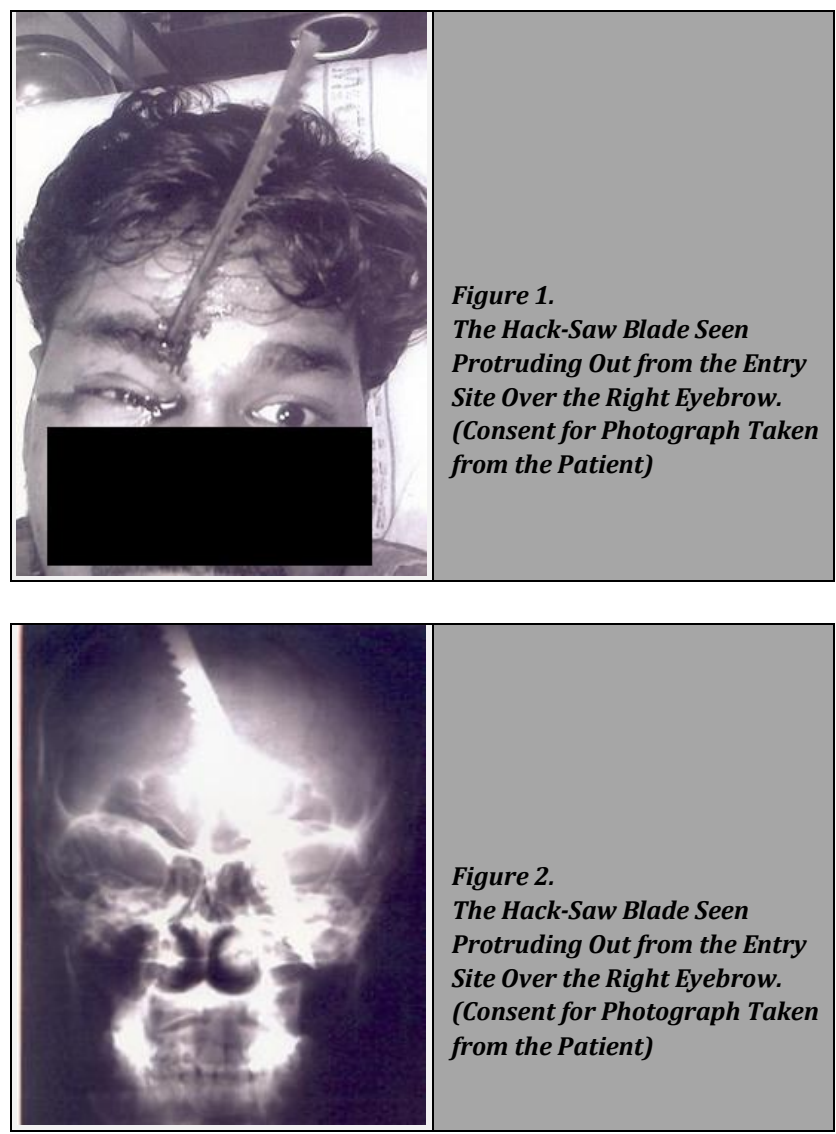

The patient was diagnosed with perforating ocular injury with retained intra ocular foreign body in the right eye. Ocular Trauma Score for the ocular injury was 2 which estimated poor visual prognosis.

The patient was immediately taken up for surgery. The foreign body was dislodged and removed. Unfortunately, the right globe had to be enucleated following the removal of the blade because it was damaged beyond repair. A corrugated rubber drain was left in the orbit after enucleation. The patient has been on regular follow up for 4 weeks and is doing well. He is scheduled to be fitted with a prosthetic implant.

\section{Case - 2}

A 20-year-old dental student presented to the emergency service with alleged history of injury to the right eye, 30 minutes prior to presentation. He was straightening the orthodontic wire which is used for making braces, using a plyer along with his batch mate when by mistake the wire recoiled and injured his right eye. He presented with redness, pain and watering in the right eye following the trauma. He was fully conscious and stable when he was brought to the emergency service. A complete general physical examination along with a thorough ocular examination was done. The visual acuity in the right eye was $6 / 24$ while the fellow eye had a visual acuity of 6/9. Extra ocular movements were within normal limits in all 6 cardinal positions. Local examination revealed periorbital oedema around the right eye. Anterior segment examination revealed circumcorneal congestion in the right eye. A full thickness, self-sealed central corneal laceration measuring $2 \mathrm{~mm}$ in size was noted. Seidel's test was negative. Anterior chamber had 4+ cells and cortical matter of the lens was seen. The orthodontic wire had torn the anterior capsule of the lens and led to formation of a traumatic cataract in the right eye. Fundus examination could not be done as the media was hazy. B-scan of the right eye was done which showed mobile internal septae in the posterior chamber which were suggestive of vitreous haemorrhage in the right eye. Examination of the fellow eye revealed no abnormalities.

Patient was diagnosed as self-sealed corneal laceration with traumatic cataract and vitreous haemorrhage in the right eye due to penetrating ocular injury. Ocular Trauma Score for the ocular injury was 4 which indicates good visual prognosis.

Patient was taken up for extraction of the traumatic cataract by small incision cataract surgery. Intraoperatively, cataractous lens was removed through the tear in the anterior capsule. A miniscule posterior capsular tear was noted which was converted into a posterior capsulotomy. Anterior vitrectomy was performed and IOL was implanted in the capsular bag. 10-o nylon suturing was done after clearing the vitreous in anterior chamber and wound area.

Post operatively, the patient recovered well and reached BCVA of $6 / 18$. However, vitreous haemorrhage was still present 1 month post cataract extraction in the right eye. Patient was then taken up for pars plana vitrectomy and endo laser retinopexy was performed around the retinal break. Patient was managed appropriately, and he followed up regularly. He reached BCVA of 6/6P in the right eye. 


\section{DISCUSSION}

Full thickness trauma to the cornea or sclera that leads to open globe injuries is an important preventable morbidity worldwide. ${ }^{10}$ These injuries can occur in any setting including recreational and sports related activities, work place, home, rural agriculture setting and road traffic accidents. ${ }^{11}$ Various studies conducted in The United States of America, Ireland and elsewhere have shown that young males under 30 years of age are the most predisposed to suffer from ocular trauma.12,13,14 This can be seen in both our cases where the patients were young males under 30 years of age.

The first case depicted a young male who had a perforating injury to the right eye. Studies have shown that perforating injuries associated with a wound $4 \mathrm{~mm}$ or longer, combined anterior and posterior segment injuries, intraocular foreign bodies and scleral wound are found to have poorer prognosis. ${ }^{15,16}$ Studies have also shown that initial visual acuity of the traumatised eye at presentation also helps in predicting the final visual outcome. Initial visual acuity of $5 / 200$ or better is associated with a favourable prognosis. ${ }^{15,16,17}$ First patient had majority of these risk factors indicating poor prognosis. Intraoperatively, globe was found to be damaged beyond repair. Also, there was presence of risk factors for development of sympathetic ophthalmia such as perforating injury, uveal tissue prolapses and size of wound more than 5 $\mathrm{mm} \cdot{ }^{18}$ It was therefore decided to enucleate the right eye and put a prosthetic implant later on.

The second case was that of a penetrating injury where orthodontic wire went through the eye and led to cataract and vitreous haemorrhage. Studies have shown that cataract surgery and vitrectomy are the most common surgical procedures performed in patients with penetrating ocular trauma. ${ }^{19}$ We performed an early removal of cataract and implanted a PCIOL in the capsular bag after performing anterior vitrectomy. Pars plana vitrectomy was performed when vitreous haemorrhage did not improve on observation for 1 month. Early surgical intervention helped in improving the visual prognosis in the patient and our patient reached BCVA of 6/6P after surgery.

\section{CONCLUSIONS}

Ocular trauma is an important and common cause of monocular blindness worldwide. With industrialization and increased dependency on machinery, the incidence of ocular trauma has increased. Perforating ocular injuries have a very poor prognosis and it is usually difficult to have functional vision or salvage the globe even after early surgical intervention. Such patients in most cases may need enucleation followed by prosthetic orbital implant. They also need to be counselled to protect the other eye from any further ocular trauma. Penetrating ocular Injuries can also significantly affect the vision of the injured eye. However, early and appropriate surgical intervention can help in not only salvaging the globe but also providing functional vision to the affected eye. The focus should lie on preventing ocular injuries by employing different strategies at industries and work places. People should be educated about the risk of ocular trauma as well as provided with appropriate protective glasses/equipment at their work place.

Financial or other competing interests: None.

Disclosure forms provided by the authors are available with the full text of this article at jemds.com.

\section{REFERENCES}

[1] Acar U, Tok OY, Acar DE, et al. A new ocular trauma score in pediatric penetrating eye injuries. Eye (Lond) 2011;25(3):370-4.

[2] Parver LM. Eye trauma. The neglected disorder. Arch Ophthalmol 1986;104(10):1452-3.

[3] Négrel AD, Thylefors B. The global impact of eye injuries. Ophthalmic Epidemiol 1998;5(3):143-69.

[4] Pizzarello LD. Ocular trauma: time for action. Ophthalmic Epidemiol 1998;5(3):115-6.

[5] Kuhn F, Morris R, Witherspoon CD, et al. The Birmingham eye trauma terminology system (BETT). J Fr Ophtalmol 2004;27(2):206-10.

[6] Kanski JJ. Trauma. In: Kanski JJ, ed. Clinical ophthalmology. $5^{\text {th }}$ edn. London: Butterworth Heinemann 2003.

[7] Panda A, Bhatia IM, Dayal I. Ocular injuries- a socioeconomic importance. Afro-Asian J Ophthal 1985;111:163-74.

[8] Negrel AD. Magnitude of eye injuries worldwide. J Comm Eye Health 1997;10(24):49-53.

[9] Yu TSI, Liu H, Hui K. A case-control study of eye injuries in the workplace in Hong Kong. Ophthalmology 2004;111(1):70-4.

[10] Oluyemi F. Epidemiology of penetrating eye injury in Ibadan: a 10-year hospital-based review. Middle East Afr J Ophthalmol 2011;18(2):159-63.

[11] Parmar IPS, Nagpal RC, Sunandan S. Pattern of ocular injuries in Haryana. Indian J Ophthalmol 1985;33(3):1414.

[12] Klopfer J, Tielsch JM, Vitale S, et al. Ocular trauma in the United States. Eye injuries resulting in hospitalization, 1984 through 1987. Arch Ophthalmol 1992;110(6):83842.

[13] Canavan Y, O'Flaherty M, Archer D, et al. A 10 year survey of injuries in Northern Ireland 1967-76. Br J Ophthalmol 1980;64(8):618-25.

[14] Tielsch J, Parver L, Shankar B. Time trends in the incidence of hospitalised ocular trauma. Arch Ophthalmol 1989;107(4):519-23.

[15] Quah B, Yeo Y, Ang C. A retrospective study of open globe injuries seen at Singapore National Eye Centre (SNEC) in 1995. Asia Pac J Ophthalmol 1997;9(2):18-23.

[16] De Juan E, Sternberg P, Michels R. Penetrating ocular injuries. Types of injuries and visual results. Ophthalmology 1983;90(11):1318-22.

[17] Williams D, Mieler W, Abrams G, et al. Results and prognostic factors in penetrating ocular injuries with retained intraocular foreign bodies. Ophthalmology 1988;95(7):911-6. 
[18] Lim W, Chee S, Sng I, et al. Immunopathology of progressive subretinal fibrosis: a variant of sympathetic ophthalmia. Am J Ophthalmol 2004;138(3):475-7.
[19] Yüksel H, Türkcü F, Çınar Y, et al. Etiology and prognosis of penetrating eye injuries in geriatric patients in the Southeastern region of Anatolia Turkey. Ulus Travma Acil Cerrahi Derg 2014;20(4):253-7. 